history. Thus, changing the CS contingency resulted only in tentative evidence for reduced resistance, while presenting a shock contingent upon a response resulted in significant changes in resistance to extinction. These effects may be interpreted in terms of the competing processes which are involved.

\section{REFERENCES}

BEECROFT, R. S. Near-goal punishment of avoidance running. Psychonomic Science, $1967,8,109-110$.

BAUM, M, Extinction of avoidance responding through response prevention (flooding). Psychological Bulletin, 1970, 74, 276-284.

BAUM, M.. \& OLER, I. D. Extinction of avoidance responding. Psychological Reports, 1968, 23, 807-813.

BROWN, J, S.. MARTIN, R. C., \& MORR $O W, M$. W. Self-punitive behavior in the rat: Facilitative effects of punishment of resistance to extinction. Journal of Comparative \& Physiological Psychology, 1964, 57, 127-133.

CAMPBELL, B. A., SMITH, N. R., \& MISANIN, J. B. Effects of punishment on extinction of avoidance behavior: Avoidance-avoidance conflict or vicious circle behavior? Journal of Comparative $\&$ Physiological Psychology, 1966, 62. 495-498.

CHURCH, R. M. The varied effects of punishment on behavior. Psychological Review, 1963, 70, 369-402.

D'AMATO. M. R.: KELLER, R. D., \& DI CARA, L. Facilitation of discriminated avoidance leaming by discontinuous shock. Journal of Comparative \& Physiological Psychology. $1964,58,344-349$.

HERRNSTEIN, R. J., \& HINELINE, P. N. Negative reinforcement as shock-frequency reduction. Journal of the Experimental Analysis of Behavior. 1966, 9, 421-430.

KATZEV, R. Extinguishing avoidance responses as a function of delayed warning signal termination. Journal of Experimental Psychology, 1967, 75. 339-344.

MCKEARNEY, J. W. Maintenance of responding under a fixed-interval schedule of electric shock presentation. Science, $1968,160,1249-1251$

SANDLER, J.. DAVIDSON, R. S. GREENE, W. E., \& HOLZSCHUH, R. D. Effects of punishment intensity on instnumental avoidance behavior. Journal of Comparative \& Physiological Psychology, 1966, 61, 21 2-216.

SOLOMON, R. L.. KAMIN, L. J. \& WYNN, L. C. Traumatic avoidance learning: The outcomes of several extinction procedures with dogs. Journal of Abnormal \& Social Psychology, 1953, 48, 291-302.

STRETCH, R., ORLOFF, E. R., \& DALRYMPLE, S. D Maintenance of responding by fixed-interval schedule of electric shock presentation in squirrel monkeys. Science, $1968,162,583-585$.

\title{
Omission training effects following VI and FI pretraining*
}

\section{JEFF S. TOPPING, JOHN W. PICKERING, and JERRY A. JACKSON $\dagger$ Mississippi State University, State College, Miss. 39762}

The present study assessed the relative response-elimination properties of three omission training procedures following VI and FI 20-sec pretraining. During omission training, response-reinforcement and reinforcement-reinforcement intervals both were 5,20 , or $35 \mathrm{sec}$. Regardless of the pretraining reinforcement schedule, the 5- and $35-\mathrm{sec}$ groups showed the greatest and most rapid response reduction. However, findings from a durability test indicated that the response elimination of the 5-sec groups was very transient, whereas it was long lasting in the 20-and $35-\mathrm{sec}$ groups.

In recent years, attention has focused on the various techniques for eliminating responding. One particular response-elimination technique which has generated considerable research is omission training (OT), in which $\mathrm{S}$ is reinforced for omitting a previously reinforced response. Several investigations have shown OT to be a successful method of response

* Supported in part by National Science Foundation Institutional Grant for Science R 200J-4450.

tRequests for reprints should be sent to Jeff S. Topping, P.O. Drawer PF, Mississippi State University. State College, Miss. 39762. elimination (Baer, Peterson, \& Sherman, 1967; Long, 1962, 1963; Mishkin \& Weiskrantz, 1959 ; Reynolds, 1961; Sherman, 1965). In addition, OT alone has been observed to produce relatively more durable effects than extinction training alone, extinction training plus punishment, or OT plus punishment (Uhl \& Garcia, 1969; Uhl \& Sherman, 1971).

Two temporal parameters are involved in the OT procedure: (1) a response-reinforcement interval which specifies the time that each response postpones reinforcement, and (2) a reinforcement-reinforcement interval which specifies the time between reinforcements if no responses are emitted. Recent investigations in our laboratory have suggested that the relationship between these two temporal parameters and the pretraining schedule of reinforcement might be crucial in determining the effects of OT.

The present experiment attempted to provide additional information on the relationship between $O T$ and the pretraining schedule of reinforcement. This aim was accomplished by pretraining Ss on either a variable-interval (VI) 20 -sec or fixed-interval (FI) 20-sec schedule and then switching to OT, in which the response-reinforcement and reinforcement-reinforcement intervals were greater than, equal to, or less than the numerical value of the pretraining schedule.

\section{SUBJECTS}

Twelve experimentally naive male White King pigeons, individually housed, served as Ss and were maintained at approximately $75 \%$ of their free feeding weights for a period extending from 1 week prior to the experiment through the duration of the experiment.

$$
\text { APPARATUS }
$$

A standard three-key pigeon chamber, $19 \frac{1 / 2}{2} \times 14 \times 14$ in., was located within a sound-attenuating ventilated cubicle. The 1 -in.-diam keys were centered, $10 \mathrm{in}$. from the floor and 4 in. apart, on a metal panel separating the S's chamber from the area containing the stimulus- and food-presenting mechanisms. Only the center key was employed in the present experiment, and the remaining keys were covered by metal plates. A minimum force of $15 \mathrm{~g}$ was required to operate the $\mathrm{key}$, and responses produced auditory feedback. A one-plane readout allowed white light to be projected on the response key, and the experimental chamber was diffusely lighted from above by two small lightbulbs. Three inches from the bottom of the intelligence panel was centered a $2 \times 2 \mathrm{in}$. opening, through which a solenoid-operated grain hopper could be presented. Reinforcement consisted of a $5 \mathrm{sec}$ access to the illuminated grain hopper. A white-noise generator functioned throughout the experiment to mask extraneous noises, and a blower regulated the temperature inside the chamber. A system of automatic controlling and recording equipment allowed the data to be collected in a separate room.

\section{PROCEDURE}

As soon as Ss were reduced to $75 \%$ of their ad lib weights, they were given 2 days of magazine training, during which 50 reinforcements were 
Table 1

Individual Transformed Response Rates

\begin{tabular}{|c|c|c|c|c|c|c|}
\hline & & & & on $\mathrm{T}$ & & $\begin{array}{c}\text { Durability } \\
\text { Test }\end{array}$ \\
\hline & & & & & & \\
\hline & & $\mathbf{S}$ & $1-2$ & $3-4$ & $5-6$ & $7-8$ \\
\hline & OT 5 & 1 & .10 & .00 & .00 & .24 \\
\hline & & 2 & .16 & .01 & .01 & .27 \\
\hline VI & OT 20 & 3 & .20 & .04 & .02 & .02 \\
\hline & & 4 & .28 & .02 & .00 & .01 \\
\hline & OT 35 & 5 & .09 & .05 & .02 & .01 \\
\hline & & 6 & .17 & .01 & .00 & .00 \\
\hline & OT 5 & 7 & .17 & .02 & .02 & .29 \\
\hline & & 8 & .11 & .02 & .00 & .27 \\
\hline FI & OT 20 & 9 & .27 & .05 & .01 & .00 \\
\hline & & 10 & .23 & .03 & .00 & .00 \\
\hline & OT 35 & 11 & .17 & .01 & .01 & .00 \\
\hline & & 12 & .12 & .02 & .00 & .00 \\
\hline
\end{tabular}

delivered daily according to a noncontingent VI $20-\mathrm{sec}$ schedule. During the next 4 days, Ss were shaped (CRF) to peck the response key and allowed to make $\mathbf{5 0}$ continuously reinforced responses daily. Half of the Ss were then gradually introduced to a contingent VI 20-sec schedule, while the remainder were reinforced according to a contingent FI 20 -sec schedule. All Ss received a total of 20 daily sessions on their respective schedules, with sessions terminating after 50 reinforcements had been produced.

Following pretraining, all Ss were switched to OT. Responsereinforcement and reinforcementreinforcement intervals of 5,20 , or $35 \mathrm{sec}$ were used, with two of the six VI and FI Ss being exposed to each value. All Ss received 6 days of OT, with sessions lasting $20 \mathrm{~min}$ or 50 reinforcements, whichever occurred first.

After completion of OT, a durability test of response elimination was conducted. Ss were returned to their respective VI 20 -sec or FI 20 -sec schedules, although reinforcements were now presented noncontingently. Durability testing lasted for two daily 20-min sessions.

\section{RESULTS}

Table 1 presents the individual mean response rates during $O T$ and durability testing, in 2-day blocks, transformed by the shape function technique of Anderson (1963). The transformation treated each S's daily response rate as a proportion of his mean response rate during the final two sessions of pretraining, i.e., a transformed value of 1 indicates responding at the same rate as at the end of pretraining and a transformed value of 0 indicates complete or nearly complete cessation of responding.

A 2 (pretraining schedule) by 3 (groups) by 3 (blocks of days) repeated-measures ANOVA was performed on the OT data in Table 1. This analysis yielded significant groups $(\mathrm{F}=11.92, \mathrm{df}=2 / 6, \quad \mathrm{p}<.01)$ and days $(F=110.50, \mathrm{df}=2 / 12, \mathrm{p}<.001)$ main effects, as well as a significant Groups by Days interaction $(F=5.11$, $\mathrm{df}=4 / 12, \mathrm{p}<.05)$. With respect to the groups effect, Newman-Keuls tests indicated that the OT 5- and OT 35-sec groups differed significantly $(p<.01)$ from the OT 20 -sec group, although they did not differ significantly from each other.

A separate 2 (pretraining schedule) by 3 (groups) ANOVA was performed on the durability testing data in Table 1. This analysis revealed only a significant groups effect $(F=735.20$, $\mathrm{df}=2 / 6, \quad \mathrm{p}<.001)$. Subsequent Newman-Keuls tests showed that the OT 5-sec groups did not differ significantly from each other, nor did any of the OT 20- and OT 35-sec groups differ significantly; however, the OT 5-sec groups were significantly different $(\mathrm{p}<.01)$ from all the other groups.

DISCUSSION
The obtained results extend the previous findings on OT by suggesting that the values of the response-reinforcement and reinforcement-reinforcement interval are very important in determining the response-elimination effectiveness of OT.

As noted by Uhl \& Sherman (1971), the efficacy of a response-elimination technique should be determined by the durability, and not the immediacy, of its effects. In this regard, examination of the present findings from the durability test are quite informative. That is, Ss in the OT 5-sec groups, regardless of VI or FI pretraining, showed the most immediate but the least durable response elimination. Conversely, Ss in the OT 20-sec groups were slower in reducing responding, but displayed much greater durability.
Uhl \& Garcia (1969) trained their Ss on a VI 30-sec schedule before initiating OT. They observed that Ss $h$ a ving response-reinforcement and reinforcement-reinforcement intervals less than or greater than $30 \mathrm{sec}$ emitted fewer responses during OT than Ss whose temporal intervals were equal to $30 \mathrm{sec}$. Results of the present experiment replicated this unexpected finding in that OT 5- and $35-\mathrm{sec}$ Ss responded considerably less than OT 20 -sec Ss. This pattern was found in both the VI and FI 20 -sec pretraining conditions. Apparently, a change from the available frequency of reinforcement during pretraining, in either a higher or lower direction, facilitates response elimination in OT.

Taken together, these findings emphasize the importance which should attend to the selection of the response-reinforcement and reinforcement-reinforcement values, especially in relation to the preceding reinforcement frequency parameter, in attempts to introduce the OT paradigm. In addition, selection of these temporal intervals should take into consideration whether immediate and/or longer-lasting response elimination is desired. Finally, the relative similarity of results from the two pretraining conditions suggests that the type of reinforcement schedule used, at least as far as VI and FI are concerned, is not crucial.

\section{REFERENCES}

ANDERSON, N. H. Comparisons of different populations: Resistance to extinction and transfer. Psychological Review, 1963, 70, 162-179.

BAER, D. M., PETERSON, R. F., \& SHERMAN, J. A. The development of imitation by reinforcing behavioral similarity to a model. Journal of the Experimental Analysis of Behavior, 1967. $10,405-416$

LONG, E. R. Additional techniques for producing multiple-schedule control in children. Journal of the Experimental Analysis of Behavior, 1962, 5, 443-455.

LONG, E. R. Chained and tandem scheduling with children. Journal of the Experimental Analysis of Behavior, 1963. 6, 459-472

MISHKIN M. WEISKRANTZ, L, Effects of cortical lesions in monkeys on critical flicker frequency. Journal of Comparative \& Physiological Psychology, 1959, 52, 660-666.

REYNOLDS, G. S. Behavioral contrast. Journal of the Experimental Analysis of Behavior, 1961, 4, 57-71.

SHERMAN, J. A. Use of reinforcement and imitation to reinstate verbal behavior in mute psychotics. Journal of Abnormal Psychology, 1965, 70, 155-164.

UHL, C. N. \& GARCIA. E. E. Comparison of omission with extinction in response elimination in rats. Journal of Comparative \& Physiological Psychology, $1969,69,554-562$

UHL C. N., \& SHERMAN, W. $O$ Comparison of combinations of omission, punishment, and extinction methods in response elimination in rats. Journal of Comparative \& Physiological Psychology, 1971. 74, 59-65. 